\title{
Study on Sustainable Development of the Transnational Power Grid Interconnection Projects under Diversified Risks Based on Variable Weight Theory and Bayesian Network
}

\author{
Hao Wang, ${ }^{1}$ Yanan Jin, ${ }^{2}$ and Xin Tan $\mathbb{D}^{3}$ \\ ${ }^{1}$ Information and Control Engineering, Liaoning Shihua University, Fushun 113006, China \\ ${ }^{2}$ Industrial Engineering, North China Electric Power University, Baoding 071000, China \\ ${ }^{3}$ China Energy Engineering Group Jiangsu Power Design Institute Co., Ltd, Nanjing 211102, China \\ Correspondence should be addressed to Xin Tan; tanxin_ie2011@163.com
}

Received 11 December 2019; Accepted 14 February 2020; Published 11 March 2020

Academic Editor: Renata Archetti

Copyright (c) 2020 Hao Wang et al. This is an open access article distributed under the Creative Commons Attribution License, which permits unrestricted use, distribution, and reproduction in any medium, provided the original work is properly cited.

Transnational power grid interconnection is an important measure to promote the construction of energy Internet. It can meet the global power demand in a clean and green way, promote the UN's concept of "sustainable energy," and tackle climate changes. But, transnational power grid projects face many complex and variable risks due to their complex background and lacking experience. According to the characteristics of transnational power grid interconnection projects, a risk assessment index system including 10 indexes such as national relation, public participation, and available transmission capacity is constructed. Then, in order to overcome the shortcomings of traditional risk assessment methods, this paper proposes a risk assessment method combined with risk theory and probabilistic model, which can not only consider the uncertainties but also integrate the probability of accidents with consequences. Therefore, it can effectively assess the transnational power grid interconnection projects under diversified risks. In addition, in order to further magnify the impact of higher risks on such projects, a method combining traditional weighting method with the variable weight theory is proposed. The study in this paper provides certain guidance and decision-making support for different participants such as the government power sector, construction enterprises, and investment enterprises when they launch on sustainable development of the transnational project business, which have obvious practical significance.

\section{Introduction}

The world's energy development is facing three challenges: resource constraints, environmental pollution, and climate change. The fundamental solution is to establish a safe, clean, and sustainable energy security system. The essence of building a global energy Internet is to build a green, lowcarbon, interconnected, and shared world energy community. Strengthening international power cooperation and actively encouraging power companies to participate in the construction of transnational projects are inevitable requirement for promoting global power demand in a clean and green way. Moreover, with the gradual opening of the power market and the rapid development of power technology, the scale and quantity of transnational power grid interconnection projects will enter a new stage of development in the future. In recent years, China State Grid Corporation has attached great importance to international cooperation in the energy and power development, follows the principles of consultation, co-construction, and sharing, and adopts a market-oriented approach to successfully achieve "going out." In terms of strengthening international cooperation in energy and power development, China State Grid Corporation has steadily invested in energy infrastructure. It has successfully operated the backbone energy network of several countries and regions including the Philippines, Brazil, Italy, and Greece. In addition, it has actively carried out transnational transmissions with neighboring countries and has built many transmission lines connecting Russia, Mongolia, Kyrgyzstan, and so on [1]. In 
the process of developing international business, China State Grid Corporation adheres to localized development and takes an active part in public welfare, thus wins the trust and recognition of local people [2]. However, due to the fact that various stakeholders in the transnational power grid interconnection projects have just entered the international project market and are not yet familiar with the conditions and rules of the international project market, there are still high risks in international projects, which make it difficult for enterprises to coordinate projects. In addition, international projects have the characteristics of large scale, long-construction period, and complex structure. Therefore, during the construction stage, it will be interfered by various external factors, including political environment, economic environment, design changes, and so on. These factors are more complex, which lead to more risks and losses [3]. Therefore, it is very necessary to study the sustainable development of the transnational power grid interconnection projects under diversified risks.

At present, there are few literature studies on the sustainable development of the transnational power grid interconnection projects under diversified risks, and studies on related fields are still at a preliminary stage. However, the current stage of study on the sustainable development of the national power grid interconnection projects under diversified risks has become more mature. Zhao and Guo [4] pointed out that UHV power transmission project is a high-tech power grid project that faced with many risks and uncertainties and used the analytic hierarchy process and the fuzzy comprehensive assessment method for risk assessment. Zhao and Li [5] added the policy and legal risks to the previous study on UHV transmission project risk assessment and combined the superiority of cloud model random reflection. Liu et al. [6] synthetically considered the structural attributes, state attributes, and social attributes of each component in the system and proposed a grid security risk assessment method that takes into account the integrated importance of components. Li et al. [7] identified the political, legal, social, and environmental risks of the Qinghai-Tibet power grid interconnection project and then used the matter-element extension model to assess it, which provided reference for project superintendent and related stakeholders. Through a questionnaire survey, Wu et al. [8] identified 44 risk factors such as government intervention, environmental risks, and inadequate regulatory systems and then calculated the degree of impact and the diversified grade of each risk factor by the fuzzy comprehensive assessment method. Han et al. [9] regarded the "wind power-energy storage system" and "wind power-regenerative electric boiler" as the game's participants and the maximum daily benefit of the system as the objective function and established an economic assessment model of the integrated energy system to consume the curtailed wind based on game theory. Li et al. [10] combined the life cycle assessment (LCA) method and fuzzy rough sets (FRS) theory to build an environmental assessment model for a distributed renewable energy system.

There is relatively mature international project risk index system and assessment model, but a systematic study of risk assessments for the characteristics of transnational power grid interconnection projects has not yet been developed. Feng [11] analyzed the political risks of international highway BOT projects deeply, including national risks, government default risks, and legal risks. Shao et al. [12] constructed an assessment index system that includes political risk, economic risk, construction risk, and management risk for international projects. In addition, he used the evidence theory to carry out dimension reduction and risk assessment of the international project. Bai and Gao [13] classified the risks of international interconnection projects as political risk, economic risk, management risk, and environmental risk and proposed corresponding countermeasures and preventive measures. Lee et al. [14] focused on Asia-centric international codevelopment projects and identified key risk indexes as demand environment, market risk, and construction capacity. Huang and SuiKe [15] systematically analyzed the risk factors of international projects from the perspective of multidimension features, including policy risks, market risks, and management risks. Huang and Wang [16] constructed a risk assessment index system including political risk, social-cultural risk, and technical risk based on the characteristics of international projects. Bekaert et al. [17] proved that the assumption of sovereign spreads was decentralized, and there was a flaw in the method of expanding the project discount rate through such spreads. They proposed "political risk spreads" to eliminate double counting. Min et al. [18] proposed a standardized risk management method for the international nuclear power plant project. The method includes standard risk classification and structured risk assessment techniques for different types of power plants, such as specific gravity and probability. Li et al. [19] built a comprehensive risk assessment index system and criteria including 11 indexes: national relation, terrorist attacks, and so on. Through the analysis of internal and external risk factors that transnational power networking projects may face, they adopted granular computing to determine the index weights. Yanmei and Zeng [20] constructed a regional electrical energy substitution potential evaluation index system based on comprehensive consideration of the influencing factors and regional differences in the potential of electrical energy substitution in order to illustrate the feasibility. The improved Technique for Order Preference by Similarity to an Ideal Solution (TOPSIS) assessment model by connection degree was used to assess the potential of electrical energy substitution in each region. Wang et al. [21] constructed an evaluation index system for sustainability of water environment treatment PPP projects covering five aspects: economy, society, resources and environment, engineering, and project management. Considering the randomness and fuzziness of the sustainable evaluation system, the cloud model was introduced to describe the sustainable properties of the project, and the uncertainty measurement of the sustainable PPP project for water environment management was realized.

In the context of energy, insufficient risk identification and control of transnational power grid construction will not only cause enterprises to suffer high economic losses but also affect the diplomatic relations and the deployment of energy strategies, even hinder the progress of energy interconnection. The purpose of this paper is to improve the scientific and sustainability of transnational power grid interconnection projects and to establish a risk analysis and 
assessment method for identifying such projects and propose a risk assessment index system for the characteristics of transnational projects. This paper uses the matter-element extension model to calculate degree of closeness and introduced Bayesian network model to get the risk grades under various scenarios and probabilities. In order to further amplify the impact of higher risks on transnational power grid interconnection projects, this paper adopts variable weight theory to adjust the index weights. The transnational power grid interconnection will greatly promote the communication and trade between interconnection countries. Thus, the study stimulates economic growth and drives emerging industries such as smart grid, UHV, and new energy. The study on sustainable development of the transnational power grid interconnection projects under diversified risks also has certain value in economic and environmental benefit assessment of energy interconnection projects. This paper helps to enhance the risk management capabilities of transnational power grid interconnection projects. At the same time, it can provide certain experiences and references for such projects at the planning stage, which have important theoretical and practical significance.

\section{Methods}

Based on the construction of the transnational power grid interconnection project risk assessment index system, this paper proposes the only reference comparison judgment method and the matter-element extension model to establish a project risk assessment model. In addition, this paper adopts a Bayesian network to carry out uncertainty forecast of risk indexes and variable weight theory to magnify the impact of high risks on such projects. The detailed process is shown in Figure 1.

2.1. Bayesian Network. Bayesian network is a graphical network based on probabilistic reasoning and has great advantages in solving the risks caused by the uncertainty and association of complex systems. With these advantages, it has been widely used in many fields [22]. Its basic step is as follows:

Step 1. Identify the target model and establish the variables and their interpretation associated with the target model.

Step 2. Correspond the nodes with variables and the directed side with the conditional dependence between variables after establishing a directed acyclic graph network that denotes diversified variables. It can be calculated as follows:

$$
P(U)=P\left(X_{1}, X_{2}, \ldots, X_{n}\right)=\prod_{i=1}^{n} P\left(X_{i} \mid \mathrm{Pa}_{i}\right),
$$

where $\mathrm{Pa}_{i}$ is the parent node set of $X_{i}$.

Step 3. Assign conditional probability distribution $P\left(X_{i} \mid \mathrm{Pa}_{i}\right)$ to each node.
2.2. Only Reference Comparison Judgment Method (G2 Method). The choice of weighting method directly affects the feasibility and quality of project risk assessment. At present, the weights are determined by many methods: the analytic hierarchy process [23], the rough set conditional information entropy [24], the principal component analysis method [25], and the order relation method [26]. In this paper, according to the actual situation of the project and assessment objective, the only reference comparison judgment method is used to determine the weight of risk assessment indices. The only reference comparison judgment method is a weighting method on the basis of the order relation method, which can better reflect the risk consciousness of the assessment experts [27]. Its basic step is as follows:

Step 1. Select the most unimportant and unique index in the index set $\left\{x_{k}\right\}(k=1,2, \ldots, n)$, and then make indexes $x_{1}, x_{2}, \ldots, x_{n}$ as $x_{k 1}, x_{k 2}, \ldots, x_{k n}$ ( $x_{k n}$ is the most unimportant index).

Step 2. Make the rational judgment $r_{\text {in }}$ of the ratio of the importance of assessment indexes $x_{k i}$ and $x_{k n}$ according to the project experiences, that is,

$$
r_{\text {in }}=a_{i}(i=1,2, \ldots, n-1),
$$

where $a_{i}>0$ and $a_{m}=1$.

Step 3. Calculate the weight $w_{i}$ if the value of $a_{i}$ is correct:

$$
w_{i}=\frac{a_{i}}{\sum_{j=1}^{n} a_{j}}(i=1,2, \ldots, n) .
$$

2.3. Matter-Element Extension Model with Variable Weight. Matter-element extension model solves the practical problems by using the matter-element concept. It regards the extension set theory as the theoretical framework to establish the classical domain, joint domain, and assessment grade. It determines the assessment grade based on the index data [28]. Its basic step is as follows:

Step 1. Determine the matter-element matrix, the classical domain, and the joint domain to be assessed.

Matter-element matrix $R_{0}$ is expressed as

$$
R_{0}=\left(N_{0}, C_{i}, V_{i}\right)=\left[\begin{array}{ccc}
N_{0} & C_{1} & V_{1} \\
& C_{2} & V_{2} \\
& \vdots & \vdots \\
& C_{n} & V_{n}
\end{array}\right],
$$

where $N_{0}$ is the matter-element to be assessed; $C_{i}$ is $n$ characteristics of $N_{0} ; i=1,2, \ldots, n$ is the number of assessment indices; and $V_{\mathrm{i}}$ is the actual value of $N_{0}$ corresponding to $C_{i}$.

Classic domain matrix $R_{j}$ is expressed as 


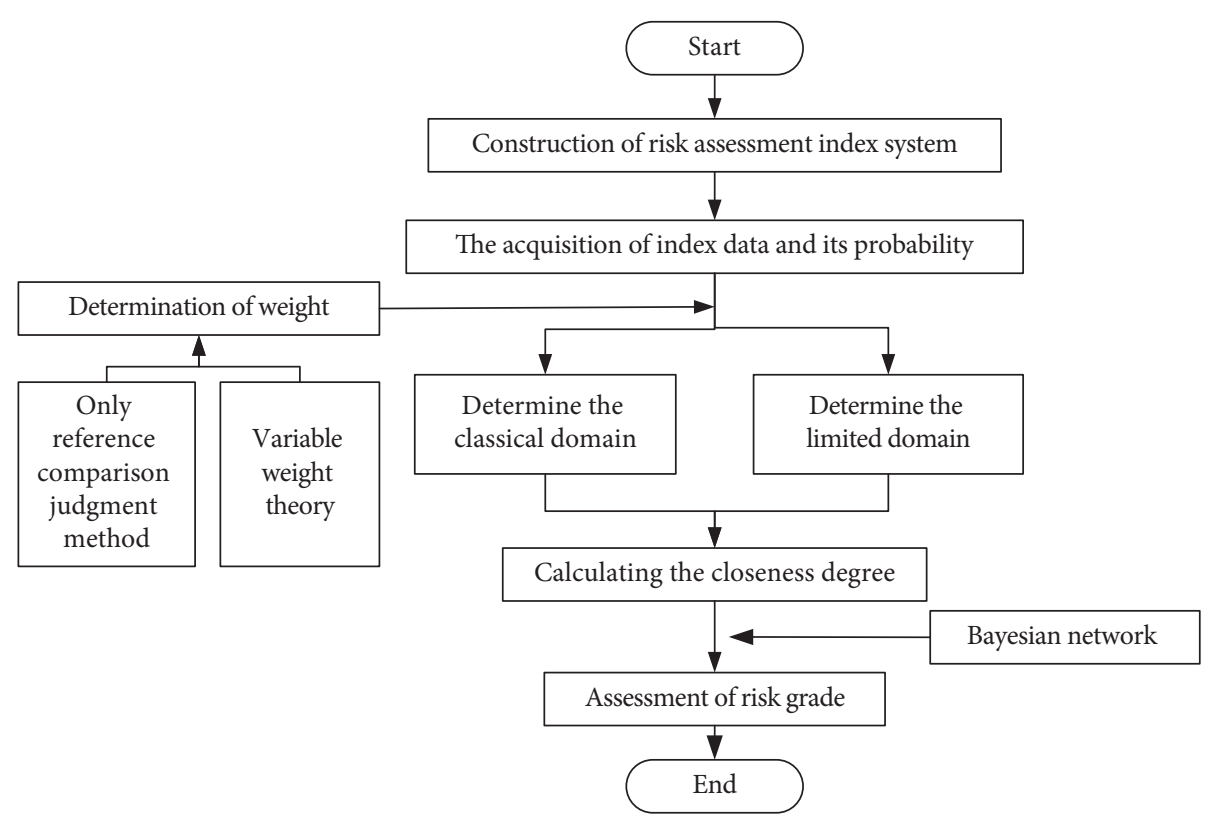

FIGURE 1: Flowchart of risk assessment of the transnational power grid interconnection projects.

$R_{j}=\left(N_{j}, C_{i}, V_{i j}\right)=\left[\begin{array}{ccc}N_{j} & C_{1} & V_{1 j} \\ & C_{2} & V_{2 j} \\ \vdots & \vdots \\ & C_{n} & V_{n j}\end{array}\right]=\left[\begin{array}{ccc}N_{j} & C_{1} & \left(a_{1 j}, b_{1 j}\right) \\ & C_{2} & \left(a_{2 j}, b_{2 j}\right) \\ \vdots & \vdots \\ & C_{n} & \left(a_{n j}, b_{n j}\right)\end{array}\right]$,

where $N_{j}$ is the $j$-th assessment grade divided; $V_{i j}$ is the range of $N_{j}$ corresponding to $C_{i}$, which is the classical domain; and $a_{i j}$ and $b_{i j}$ are the upper and lower limit of $V_{i j}$, respectively, $j=1,2, \ldots, m$.

Joint domain matrix $R_{p}$ is expressed as

$$
R_{\mathrm{p}}=\left(N_{p}, C_{i}, V_{\mathrm{pi}}\right)=\left[\begin{array}{ccc}
N_{p} & C_{1} & V_{p 1} \\
& C_{2} & V_{p 2} \\
& \vdots & \vdots \\
& C_{n} & V_{\mathrm{pn}}
\end{array}\right]=\left[\begin{array}{ccc}
N_{p} & C_{1} & \left(a_{p 1}, b_{p 1}\right) \\
& C_{2} & \left(a_{p 2}, b_{p 2}\right) \\
\vdots & \vdots \\
& C_{n} & \left(a_{\mathrm{pn}}, b_{\mathrm{pn}}\right)
\end{array}\right],
$$

where $N_{p}$ is the objective to be assessed and $V_{\mathrm{pi}}$ is the range of $N_{p}$ corresponding to $C_{i}$, which is the joint domain.

Step 2. Calculate weight introducing variable weight theory

Compared with the constant weight method, the variable weight method can further amplify the impact of higher risks in the process of risk assessment to better avoid the risks [29].

Let the factor state variable be $X=\left(x_{1}, x_{2}, \cdots, x_{n}\right)$, the factor constant weight variable be $W=\left(w_{1}, w_{2}, \cdots, w_{n}\right)$, and the state variable weight vector be $S(X)=\left(S_{1}(X)\right.$, $\left.S_{2}(X), \ldots, S_{n}(X)\right)$. Then, the product of the standardized Hadamard of $W$ and $S(X)$ can be obtained as

$$
\begin{aligned}
& W(X)=\left(w_{1}(X), w_{2}(X), \ldots, w_{n}(X)\right), \\
& w_{i}(X)=\frac{w_{i} S_{i}(X)}{\sum_{k=1}^{n} w_{k} S_{k}(X)}, \quad i=1,2, \ldots, n,
\end{aligned}
$$

where $S_{i}(X)=e^{\alpha\left(x_{i}-\bar{x}\right)}$, and $\alpha$ is a variable weight factor.

Step 3. Calculate closeness degree.

The traditional matter-element extension model is based on the principle of maximum degree of membership, but a large amount of information may be lost during the assessment process, which results in some assessment results inconsistent with the actual state. This paper uses closeness degree instead of the degree of membership function.

The distance between the object to be assessed and the classical domain is [29]

$$
D_{j}\left(v_{i}\right)=\left|v_{i}-\frac{a_{i j}+b_{i j}}{2}\right|-\frac{b_{i j}-a_{i j}}{2},
$$
[30]

Then, the closeness degree of the object to be assessed is

$$
K_{j}(N)=1-\sum_{i=1}^{n} D_{j}\left(v_{i}\right) w_{i}(X) .
$$

Step 4. If $K_{j}(N)=\max \left\{K_{j}(N)\right\}(j=1,2, \ldots, m)$, the object to be assessed belongs to grade $j$.

\section{Risk Assessment Index System of the Transnational Power Grid Interconnection Project}

3.1. Risk Assessment Index System. The risk assessment of the power grid projects is based on risk identification and 
relevant safety indexes. In this paper, from a comprehensive point of view, risk indexes are determined according to the comparability, operability, and design principles of each index. By summarizing, comparing, and classifying risk sources and referring to previous relevant study, this paper constructs a risk assessment index system of transnational power grid interconnection projects as shown in Table 1.

\subsection{Analysis of the Risk Assessment Index}

\subsubsection{Government Risk}

(1) National Relation. The transnational power grid interconnection projects need to be carried out in several countries or regions. The national relation among the countries or regions will have a significant impact on the construction of such projects, which is an infrastructure project with a long-construction period and tremendous significance for national defense and people's livelihood. In accordance with the degree of national relation, this paper classifies the national relation, ranks them from low to high as hostile relation, strained relation, general relation, strategic partnership, allied relation, and gives the corresponding risk grades $[80,100],[60,80],[40,60],[20,40]$, $[0,20]$.

(2) National Policy. At each construction stage of transnational power grid interconnection projects, different types of laws, regulations, and policies in different countries clearly define the working basis and operation specifications of each construction stage of such projects. Related policy changes will lead to policy discontinuities, which will bring risks to the construction of such projects. This paper uses the political system stability index (PSSI) proposed by Dan Haendel to objectively measure national policy risks.

\subsubsection{Economic Risk}

(1) Internal Rate of Return. Internal rate of return (IRR) refers to the discount rate when the total present value of capital inflows is equal to capital flows of the projects and the net present value is equal to zero. It can better reflect the economic risks that such projects may face [31]. Generally, the trial calculation method is used to calculate the internal rate of return. The equation is as follows:

$$
i^{*}=\frac{\mathrm{NPV}_{n} \times\left(i_{n+1}-i_{n}\right)}{\mathrm{NPV}_{n}+\left|\mathrm{NPV}_{n+1}\right|}+i_{n},
$$

where $i_{n}$ and $i_{n+1}$ are the lower and the higher trial discount rate and $\mathrm{NPV}_{n}$ and $\mathrm{NPV}_{n+1}$ are the corresponding net present value of $i_{n}$ and $i_{n+1}$, respectively; usually, if $i_{n+1}-i_{n} \leq 2 \%$, the value is acceptable.

(2) Fluctuation in Exchange. Since transnational power grid interconnection projects are developed among the countries or regions, the exchange rate issue is usually involved in the financial management of the project. During the construction stage of such projects, there may be factors such as the balance of payments, inflation, interest rate changes, and other factors of a country involved in the project that cause fluctuations in exchange. These factors may affect the materials and equipment costs involved in such projects and then affect the investment profits and other economic benefits in such projects, thus bring investment risks. The equation is as follows:

$$
F_{e}=\frac{\left|E^{\prime}-\mathrm{Er}\right|}{\mathrm{Er}} \times 100 \%,
$$

where $F_{e}$ is the fluctuation in exchange; $\mathrm{Er}^{\prime}$ is the possible exchange after the implementation of such projects; and Er is the exchange in the investment stage of such projects. Usually, fluctuation in exchange within $\pm 2 \%$ is acceptable.

(3) Market Risk. The reduction in power demand will have a certain impact on power sales revenue, which is the market risk. The construction of transnational power grid interconnection projects must consider the power demand of the receiving countries before feasibility study. If completed, the reduction in power demand will lead to the adjustment of power price, which will result in investment risk. The equation is as follows:

$$
M_{r}=\frac{\mathrm{Ed}^{\prime}-\mathrm{Ed}}{\mathrm{Ed}} \times 100 \%,
$$

where $M_{r}$ is the market risk; $\mathrm{Ed}^{\prime}$ is the possible power demand after the implementation of such projects; and Ed is the power demand in the investment stage of such projects. The acceptance of market risk varies from country to country.

\subsubsection{Social Risk}

(1) Public Participation. The success of projects providing resource services such as transnational power grid interconnection projects depends largely on the support and active participation of the relevant groups. The wide participation of relevant groups helps projects to understand their specific needs and to maximize the quality of project planning. The cooperation between relevant technicians and the national project team greatly reduces the risk of such projects [32]. The index data are obtained through public opinion surveys conducted by relevant technicians, national project team of the project country.

(2) Cultural Difference. As a project with international nature, the feature of transnational power grid interconnection projects is need to build and implement in several countries or regions. Different national or regional investors have different attitudes in accepting uncertainties of such projects in the investment stage, which will seriously affect the feasibility of project construction. The equation is as follows:

$$
C_{d}=\frac{\left|\mathrm{UAI}_{a}-\mathrm{UAI}_{b}\right|}{\mathrm{UAI}_{a}} \times 100 \%,
$$

where $C_{d}$ is the cultural difference; $\mathrm{UAI}_{a}$ is the uncertainty avoidance index of the domestic investor; and $\mathrm{UAI}_{b}$ is the 
TABLE 1: Risk assessment index system of transnational power grid interconnection projects.

\begin{tabular}{lcc}
\hline Object & First-level index & Second-level index \\
\hline & Government risk & National relation A1 \\
National policy A2 & Internal rate of return B1 \\
& A & Fluctuation in exchange B2 \\
& Economic risk & Market risk B3 \\
Risk of the transnational power grid interconnection projects G & B & Public participation C1 \\
& Cultural difference C2 & Extreme weather C3 \\
& Cocial risk & Available transfer capability D1 \\
& Construction management D2 \\
\hline
\end{tabular}

uncertainty avoidance index of the interconnection country investor.

(3) Extreme Weather. In the process of establishing transnational power grid interconnection projects, it may face the effect of extreme weather, which may cause risks such as delaying construction progress and increasing construction costs. The index data are obtained through consulting experts in related fields.

\subsubsection{Manage Risk}

(1) Available Transfer Capability. The interconnection system makes the long-distance and large-capacity power trading more and more frequent. At the same time, with the transmission level increases, the power grid becomes closer to its operating limit. Available transfer capability (ATC) can not only provide accurate information on current grid usage but also reflect the safety and stability of the system operation [33]. According to the definition of the North American Electric Power Reliability Committee, ATC is the transmission capacity remaining in the actual transmission network on the basis of the existing transmission contract, which can be used commercially. The equation is as follows:

$$
C_{\mathrm{ATC}}=C_{\mathrm{TTC}}-C_{\mathrm{TRM}}-C_{\mathrm{CBM}}-C_{\mathrm{ETC}}
$$

where $C_{\mathrm{TTC}}$ is the maximum transmission capacity; $C_{\mathrm{TRM}}$ is the transmission reliability margin; $C_{\mathrm{CBM}}$ is the capacity benefit margin; and $C_{\mathrm{ETC}}$ is the transmission capacity occupied by the existing transmission protocol.

(2) Construction Management. For transnational power grid interconnection projects with the long-distance and largecapacity power trading, the cost control during the construction stage has a more significant impact on the project construction. The construction stage of such projects mainly includes technical links such as infrastructure, electrical installation, and line installation. The degree of specialization and construction risk is high. In the process of project construction, the risk factors are mainly reflected in the following two aspects:

(1) Construction Safety. The actual production operations of transnational power grid interconnection projects, such as tower installation, equipment connection, and generator suspension, usually involve high-risk operations. In actual operation, equipment damage and casualties may be caused by nonstandard operation or equipment failure.

(2) Construction Schedule. Construction schedule is one of the ways to effectively control the cost of on-site construction operations. At the same time, it is also an important link to ensure the reasonable and orderly construction progress, control the construction costs, and improve the economic benefits of such projects [34].

Combined with the score by the expert, this paper gives the construction management risk, Lower, Low, General, High, and Higher corresponding scores [0,20], [20,40], $[40,60],[60,80],[80,100]$.

\section{Case Study}

On the basis of the case background of the study [35], this paper improves and supplements the necessary data which are not clearly provided in the study according to the needs of the project. In addition, the assessment index system and assessment model established in this paper are adopted for the case study to verify the accuracy of the model.

4.1. Classification of Risk Assessment Grade. Classify the risk grade of the object to be assessed into five different grades: Lower, Low, General, High, and Higher, corresponding to $N=\left(N_{1}, N_{2}, N_{3}, N_{4}, N_{5}\right)$. The score range of each grade is divided as shown in Table 2.

4.2. Measurement and Standardization of Index Data. For the transnational power grid interconnection project risk assessment, the assessment time node is used as a criterion, and then the value of each risk index in the future is classified into $n(n>1)$ possibilities and their probabilities according to the actual situation of the object and expert prediction. In order to simply calculate, this paper assumes that the five indexes including national relation, internal rate of return, public participation, cultural difference, and construction management are clear values, and each of the other indexes is classified into two possibilities. Finally, 32 circumstances can be obtained. 
Then, this paper determines the standardization criteria according to the classification rules and related standards such as "Construction Project Economic Assessment Methods and Parameters (Third Edition)," which can be seen in Table 3. And expert assessment method is used to do standardization of each index data, which can be seen in Table 4.

4.3. Determination of the Classical Domain. The classical domain of each index is listed as follows: the classical domain of "Lower" is $(0,0.2)$; "Low" is $(0.2,0.4)$; "General" is $(0.4,0.6)$; "High" is $(0.6,0.8)$; and "Higher" is $(0.8,1)$. The classical domain of different risk grades and the object to be assessed are shown as follows:

$$
\begin{aligned}
& R_{1}=\left[\begin{array}{ccc}
N_{1} & A_{1} & (0,0.2) \\
& A_{2} & (0,0.2) \\
& B_{1} & (0,0.2) \\
& B_{2} & (0,0.2) \\
& B_{3} & (0,0.2) \\
& C_{1} & (0,0.2) \\
& C_{2} & (0,0.2) \\
& C_{3} & (0,0.2) \\
& D_{1} & (0,0.2) \\
& D_{2} & (0,0.2)
\end{array}\right], \\
& R_{2}=\left[\begin{array}{ccc}
N_{2} & A_{1} & (0.2,0.4) \\
& A_{2} & (0.2,0.4) \\
& B_{1} & (0.2,0.4) \\
& B_{2} & (0.2,0.4) \\
& B_{3} & (0.2,0.4) \\
& C_{1} & (0.2,0.4) \\
& C_{2} & (0.2,0.4) \\
& C_{3} & (0.2,0.4) \\
& D_{1} & (0.2,0.4) \\
& D_{2} & (0.2,0.4)
\end{array}\right], \\
& R_{3}=\left[\begin{array}{ccc}
N_{3} & A_{1} & (0.4,0.6) \\
& A_{2} & (0.4,0.6) \\
& B_{1} & (0.4,0.6) \\
& B_{2} & (0.4,0.6) \\
& B_{3} & (0.4,0.6) \\
& C_{1} & (0.4,0.6) \\
& C_{2} & (0.4,0.6) \\
& C_{3} & (0.4,0.6) \\
& D_{1} & (0.4,0.6) \\
& D_{2} & (0.4,0.6)
\end{array}\right], \\
& R_{4}=\left[\begin{array}{ccc}
N_{4} & A_{1} & (0.6,0.8) \\
& A_{2} & (0.6,0.8) \\
& B_{1} & (0.6,0.8) \\
& B_{2} & (0.6,0.8) \\
& B_{3} & (0.6,0.8) \\
& C_{1} & (0.6,0.8) \\
& C_{2} & (0.6,0.8) \\
& C_{3} & (0.6,0.8) \\
& D_{1} & (0.6,0.8) \\
& D_{2} & (0.6,0.8)
\end{array}\right],
\end{aligned}
$$

$$
\begin{aligned}
& R_{5}=\left[\begin{array}{ccc}
N_{5} & A_{1} & (0.8,1) \\
& A_{2} & (0.8,1) \\
& B_{1} & (0.8,1) \\
& B_{2} & (0.8,1) \\
& B_{3} & (0.8,1) \\
& C_{1} & (0.8,1) \\
& C_{2} & (0.8,1) \\
& C_{3} & (0.8,1) \\
& D_{1} & (0.8,1) \\
& D_{2} & (0.8,1)
\end{array}\right], \\
& R^{\prime}=\left[\begin{array}{ccc}
P^{\prime} & A_{1} & 0.3 \\
& A_{2} & 0.38(35 \%) / 0.44(65 \%) \\
B_{1} & 0.3 \\
B_{2} & 0.81(27 \%) / 0.84(73 \%) \\
B_{3} & 0.54(44 \%) / 0.62(56 \%) \\
C_{1} & 0.22 \\
C_{2} & 0.45 \\
C_{3} & 0.18(68 \%) / 0.23(32 \%) \\
D_{1} & 0.32(48 \%) / 0.39(52 \%) \\
D_{2} & 0.81
\end{array}\right],
\end{aligned}
$$

where $R$ are the classical domains of five different risk grades and $R^{\prime}$ is the object to be assessed.

4.4. Determination of Weight Based on Variable Weight Theory. This paper preliminarily determines the weight of each index according to the only reference comparison judgment method and then uses the variable weight theory to modify each weight. In order to let the assessment object actively participate in the risk assessment, the variable weight of each index can be determined based on the actual data of the index and its joint domain. Equation (8) can be changed to

$$
w_{i}(X)=\frac{w_{i} \exp \left[\alpha\left(d_{i \max }-d_{i \min }\right)\right]}{\sum_{k=1}^{n} w_{i} \exp \left[\alpha\left(d_{i \max }-d_{i \min }\right)\right]},
$$

where $d_{i \max }=\max \left\{\left|v_{i}-a_{p i}\right|,\left|v_{i}-b_{p i}\right|\right\} ; \quad d_{i \max }=\max \left\{\mid v_{i}-\right.$ $\left.a_{p i}|,| v_{i}-b_{p i} \mid\right\} ;$ and $w_{i}$ is obtained by the only reference comparison judgment method. This paper takes a variable weight factor $\alpha=-1$ to generate $n$ dimensional punishment type state variables.

In order to highlight the advantages of variable weight, the index weights which are calculated based on the only reference comparison judgment method and the variable weight method are proposed in this paper, as shown in Table 5.

From Table 5, it can be seen that when the index value is in the risk grade including "Lower," "Low," "General," and "High," the only reference comparison judgment method and the variable weight method have little difference in the weights. While the risk grade is "Higher," such as B2 and D2, the weights obtained by the variable weight method are 
TABLE 2: Division rule of grades.

\begin{tabular}{lcccrr}
\hline Risk assessment grade $(N)$ & $N_{1}$ & $N_{2}$ & $N_{3}$ & $N_{4}$ & $N_{5}$ \\
\hline Score range & {$[0,0.2]$} & {$[0.2,0.4]$} & {$[0.4,0.6]$} & {$[0.6,0.8]$} & {$[0.8,1]$} \\
Assessment effect & Lower & Low & General & High & Higher \\
\hline
\end{tabular}

TABLE 3: Standardization criteria of each risk assessment index.

\begin{tabular}{|c|c|c|c|c|c|}
\hline \multirow{2}{*}{ Index } & \multicolumn{5}{|c|}{ Grade of risk assessment index } \\
\hline & {$[0,0.2]$} & {$[0.2,0.4]$} & {$[0.4,0.6]$} & {$[0.6,0.8]$} & {$[0.8,1]$} \\
\hline A1 & {$[0,20]$} & {$[20,40]$} & {$[40,60]$} & {$[60,80]$} & {$[80,100]$} \\
\hline A2 & {$[0,0.2]$} & {$[0.2,0.4]$} & {$[0.4,0.6]$} & {$[0.6,0.8]$} & {$[0.8,1]$} \\
\hline B1 & \multicolumn{5}{|c|}{$\geq$ Social discount rate $(7 \%)$, the project is acceptable } \\
\hline B2 & {$[0,2 \%]$} & {$[2 \%, 4 \%]$} & {$[4 \%, 6 \%]$} & {$[6 \%, 8 \%]$} & {$[8 \%, \infty]$} \\
\hline B3 & {$[0,2 \%]$} & {$[2 \%, 4 \%]$} & {$[4 \%, 6 \%]$} & {$[6 \%, 8 \%]$} & {$[8 \%, \infty]$} \\
\hline $\mathrm{C} 1$ & {$[80 \%, 100 \%]$} & {$[60 \%, 80 \%]$} & {$[40 \%, 60 \%]$} & {$[20 \%, 40 \%]$} & {$[0,20 \%]$} \\
\hline $\mathrm{C} 2$ & {$[0,0.2]$} & {$[0.2,0.4]$} & {$[0.4,0.6]$} & {$[0.6,0.8]$} & {$[0.8,1]$} \\
\hline $\mathrm{C} 3$ & {$[0,20 \%]$} & {$[20 \%, 40 \%]$} & {$[40 \%, 60 \%]$} & {$[60 \%, 80 \%]$} & {$[80 \%, 100 \%]$} \\
\hline D1 & {$[80, \infty]$} & {$[60,80]$} & {$[40,60]$} & {$[20,40]$} & {$[0,20]$} \\
\hline D2 & {$[0,20]$} & {$[20,40]$} & {$[40,60]$} & {$[60,80]$} & {$[80,100]$} \\
\hline
\end{tabular}

TABLE 4: The data and standardization result of each assessment index.

\begin{tabular}{|c|c|c|c|c|c|c|}
\hline Index & \multicolumn{3}{|c|}{ Index data (probability) } & \multicolumn{3}{|c|}{ Standardization result (probability) } \\
\hline A1 & & 30 & & & 0.3 & \\
\hline $\mathrm{A} 2$ & $0.38(35 \%)$ & & $0.44(65 \%)$ & $0.38(35 \%)$ & & $0.44(65 \%)$ \\
\hline B1 & & $13.55 \%$ & & & 0.3 & \\
\hline B2 & $8.05 \%(27 \%)$ & & $8.17 \%(73 \%)$ & $0.81(27 \%)$ & & $0.84(73 \%)$ \\
\hline B3 & $5.4 \%(44 \%)$ & & $6.2 \%(56 \%)$ & $0.54(44 \%)$ & & $0.62(56 \%)$ \\
\hline $\mathrm{C} 1$ & & $78 \%$ & & & 0.22 & \\
\hline $\mathrm{C} 2$ & & 0.45 & & & 0.45 & \\
\hline $\mathrm{C} 3$ & $18 \%(68 \%)$ & & $23 \%(32 \%)$ & $0.18(68 \%)$ & & $0.23(32 \%)$ \\
\hline D1 & $68.5 \mathrm{MW}(48 \%)$ & & $61.3 \mathrm{MW}(52 \%)$ & $0.32(48 \%)$ & & $0.39(52 \%)$ \\
\hline D2 & & 81 & & & 0.81 & \\
\hline
\end{tabular}

TABLE 5: Comparison results of two ways to determine the weight.

\begin{tabular}{ccccccccccccc}
\hline & Index & A1 & A2 & B1 & B2 & B3 & C1 & C2 & C3 & D1 & D2 \\
\hline \multirow{2}{*}{ Weight } & G2 method & 0.1478 & 0.1478 & 0.0548 & 0.1344 & 0.0940 & 0.1034 & 0.1344 & 0.0456 & 0.0723 & 0.0657 \\
& Variable weight & 0.1460 & 0.1460 & 0.0541 & 0.1438 & 0.0928 & 0.1021 & 0.1438 & 0.0450 & 0.0714 & 0.0662 \\
\hline
\end{tabular}

TABLE 6: Comparison results of two ways to assess.

\begin{tabular}{lc}
\hline Ways & Assess results \\
\hline Matter-element extension model & General \\
Matter-element extension model with Bayesian network & Low (35\%)/general (65\%) \\
\hline
\end{tabular}

larger. This is because the weights obtained by the variable weight method are related to the index values and are more sensitive to information with a risk grade of "Higher," which helps to enhance the risk management of transnational power grid interconnection projects.

4.5. Determination of the Project Risk Grade Based on the Bayesian Network. Based on the probability of each index data, Bayesian network is used to calculate the probability of each circumstance. In each circumstance, the risk grade of the transnational power grid interconnection project is determined based on the matter-element extension method. Similarly, in order to highlight the advantages of the probability model, the results based on the traditional matter-element extension model and the matter-element extension model with Bayesian network proposed in this paper are shown in Table 6.

From Table 6, it can be seen that the assess results based on the matter-element extension model with Bayesian network proposed in this paper can intuitively describe all the possibilities of each index in the future, and they have 
high understandability. Bayesian network is introduced into risk assessment of transnational power grid interconnection projects to reduce or eliminate future uncertainties and provide reference and support for investment decisionmaking of transnational power grid interconnection projects.

\section{Conclusions}

Effective risk assessment is a smooth guarantee for the transnational power grid interconnection projects. This study can reduce the risk loss to promote the sustainable development of the power grid and accelerate the realization of the global energy internet construction. The large-scale development, allocation, and utilization of clean energy can effectively promote the transformation of the energy structure. Such projects also play a role in making full use of the complementarity of energy development among countries and ultimately promote an effective solution to the problem of sustainable energy development. This paper fully considers the characteristics of such projects including multiple countries or regions, long-distance transmission, and large uncertainties in construction to propose a risk assessment model based on a combination of risk theory and probability model. At the same time, the variable weight theory is introduced to better reflect the diversified risks of transnational power grid interconnection projects. This study can provide reference for managers of such projects.

In order to better control the diversified risks in such projects, this paper puts forward some preventive measures:

(1) Government risk: strengthens government communication, creates a peaceful international environment, makes rational use of overseas agencies, and strengthens coordination and supervision

(2) Economic risk: strengthens project cost control and establishes reasonable input-output forecasting mechanism and market demand forecasting mechanism

(3) Social risk: strengthens government cooperation and properly handles cultural differences

(4) Manage risk: constructs a mathematical model for optimal allocation, determines the best installation position and compensation, improves the transmission capacity between countries, establishes a perfect project safety assurance system before construction, and conducts safety education and operation training for all construction workers.

\section{Data Availability}

The data used to support the findings of this study are available from the corresponding author upon request.

\section{Conflicts of Interest}

The authors declare that they have no conflicts of interest.

\section{Authors' Contributions}

X. T. provided methodology; H. W. wrote and prepared the original draft; and Y. J. wrote, reviewed, and edited the manuscript.

\section{Acknowledgments}

This study was supported by the Science and Technology Project of National Electric Net Ltd. (Research on Comprehensive evaluation Method of economic, social, and environmental benefits of the Transnational Power Grid Interconnection project, SGTYHT/16-JS-198).

\section{References}

[1] D. Liu, T. Li, and L. Liu, "Research on transnational economical market transaction mode," IOP Conference Series Earth and Environmental Science, vol. 189, no. 5, Article ID 052084, 2018.

[2] Z. Zhao, "Technology application and international development trend of internet of ubiquitous things and its smart grid integration," Electrotechnics Electric, vol. 7, pp. 1-4, 2019.

[3] Q. Wang, C. Gu, X. Pan, W. Shen, and J. Wu, "Research on coordination schemes of interconnected large-scale power grid security and stability control," Electrotechnics Electric, vol. 7, pp. 21-26, 2019.

[4] H. Zhao and S. Guo, "Risk evaluation on UHV power transmission construction project based on AHP and FCE method," Mathematical Problems in Engineering, vol. 2014, Article ID 687568, 14 pages, 2014.

[5] H. Zhao and N. Li, "Risk evaluation of a UHV power transmission construction project based on a cloud model and FCE method for sustainability," Sustainability, vol. 7, no. 3, pp. 2885-2914, 2015.

[6] P. Liu, L. I. Huaqiang, Z. Yang, and Z. Ke, "Power grid security risk assessment considering comprehensive element importance index," Electric Power Automation Equipment, vol. 35, no. 4, pp. 132-138, 2015.

[7] C. Li, Y. Liu, and S. Li, "Risk evaluation of Qinghai-Tibet power grid interconnection project for sustainability," Sustainability, vol. 8, no. 1, p. 85, 2016.

[8] Y. Wu, L. Li, R. Xu, K. Chen, Y. Hu, and X. Lin, "Risk assessment in straw-based power generation public-private partnership projects in China: a fuzzy synthetic evaluation analysis," Journal of Cleaner Production, vol. 161, pp. 977-990, 2017.

[9] X. Han, F. Wang, C. Tian, K. Xue, and J. Zhang, "Economic evaluation of actively consuming wind power for an integrated energy system based on game theory," Energies, vol. 11, no. 6, p. 1476, 2018.

[10] C. Li, N. Wang, H. Zhang et al., "Environmental impact evaluation of distributed renewable energy system based on life cycle assessment and fuzzy rough sets," Energies, vol. 12, no. 21, p. 4214, 2019.

[11] N. Feng, "Political risk evaluation and prevention for international bot highway project," Northern Communications, vol. 5, pp. 126-128, 2010.

[12] J. Y. Shao, K. T. Dong, H. Guo, and H. Zhao, "Research on risk evaluation for international construction projects," Journal of Engineering Management, vol. 25, no. 2, pp. 187-190, 2011.

[13] J. Bai and J. Gao, "Risk identification and evaluation for international project contracting project," Construction Technology, vol. 42, pp. 291-296, 2013. 
[14] J. Lee, Y. Lee, and J. Kim, "Assessing the risks of Asian development projects: a theoretical framework and empirical findings," Journal of Asian Architecture and Building Engineering, vol. 12, no. 1, pp. 25-32, 2013.

[15] Y. Huang and L. I. Sui-Ke, "Research on risk evaluation method for international engineering projects," International Journal of Plant Engineering and Management, vol. 18, no. 3, pp. 140-145, 2013.

[16] K. Huang and J. Wang, "Research on comprehensive risk assessment of international engineering projects based on fuzzy," Research on Financial and Economic Issues, vol. 4, pp. 104-109, 2014.

[17] G. Bekaert, C. R. Harvey, C. T. Lundblad, and S. Siegel, "Political risk and international valuation," Journal of Corporate Finance, vol. 37, pp. 1-23, 2016.

[18] K. Min, I. Lee, and Y. Jung, "International project risk management for nuclear power plant (NPP) construction: featuring comparative analysis with fossil and gas power plants," Sustainability, vol. 9, no. 3, p. 469, 2017.

[19] J. Li, F. Wu, J. Li, Y. Zhao, and J. Li, "Research on risk evaluation of transnational power networking projects based on the matter-element extension theory and granular computing," Energies, vol. 10, no. 10, p. 1523, 2017.

[20] L. Yanmei and C. Zeng, "Evaluation index system and evaluation method of China's regional potential for electrical energy substitution," Mathematical Problems in Engineering, vol. 2018, Article ID 3834921, 16 pages, 2018.

[21] L. Y. Wang, Q. Xia, H. M. Li, and Y. Ma, "Integrated sustainability assessment of PPP projects for water environmental treatment-taking the PPP project of water environment management in Xuchang City, Henan province as an example," Resource Development \& Market, vol. 36, no. 1, pp. 1-7, 2020.

[22] X. Z. Zhang and J. University, "Research on demand forecasting in supply chain uncertainty-taking Bayesian network as the model," Sci-tech Innovation and Productivity, vol. 277, pp. 50-55, 2017.

[23] S. Thanki, K. Govindan, and J. Thakkar, "An investigation on lean-green implementation practices in indian smes using analytical hierarchy process (ahp) approach," Journal of Cleaner Production, vol. 135, pp. 284-298, 2016.

[24] X. Bao and Y. Liu, "A new method of ascertaining attribute weight based on rough sets theory," in Proceedings of the International Conference on Electronic Commerce and Business Intelligence, Beijing, China, June 2009.

[25] X. Han, Y. Sun, F. Sun, and S. Wang, "Method of determining index weight based on principal component analysis," Journal of Sichuan Ordnance, vol. 33, no. 10, pp. 124-126, 2012.

[26] H. Chen, G. Xie, and C. Wang, "Evaluation of electricity market supervision index system based on order relationship analysis," Computer and Digital Engineering, vol. 46, no. 5, pp. 941-944, 2018.

[27] J. Ma and X. Liu, "Conditional characteristic evaluation based on G2-entropy weight method for low-voltage distribution network," Electric Power Automation Equipment, vol. 37, no. 1, pp. 41-46, 2017.

[28] Q. Wu and C. Peng, "Comprehensive benefit evaluation of the power distribution network planning project based on improved iahp and multi-level extension assessment method," Sustainability, vol. 8, no. 8, p. 796, 2016.

[29] Y. Liu, W. Tao, and K. Zhou, "Comprehensive evaluation on secondary equipment condition based on matter-element extension model with variable weight," Power System Protection and Control, vol. 45, no. 8, pp. 80-85, 2017.
[30] J. L. Deng, "Introduction to grey system theory," The Journal of Grey Theory, vol. 1, no. 1, pp. 1-24, 1989.

[31] C.-B. Li, G.-S. Lu, and S. Wu, "The investment risk analysis of wind power project in China," Renewable Energy, vol. 50, no. 3, pp. 481-487, 2013.

[32] C. E. Mueller, S. I. Keil, C. Bauer, C. E. Mueller, S. I. Keil, and C. Bauer, "Effects of spatial proximity to proposed highvoltage transmission lines: evidence from a natural experiment in lower saxonyffects of spatial proximity to proposed high-voltage transmission lines: evidence from a natural experiment in lower saxony," Energy Policy, vol. 111, pp. 137-147, 2017.

[33] D. Shi, L. Gang, J. Chen, X. Duan, D. Jie, and X. U. Youping, "Fast calculation of available transfer capability in bulk interconnected grid considering directions and risks," in Proceedings of the IEEE Power and Energy Society General Meeting, San Diego, CA, USA, July 2012.

[34] R. Rao, X. Zhang, Z. Shi, K. Luo, Z. Tan, and Y. Feng, "A systematical framework of schedule risk management for power grid engineering projects' sustainable development," Sustainability, vol. 6, no. 10, pp. 6872-6901, 2014.

[35] J. Li, J. Xu, and X. Tan, "Dynamic comprehensive benefit evaluation of the transnational power grid interconnection project based on combination weighting and TOPSIS grey projection method," Sustainability, vol. 10, no. 12, p. 4672, 2018. 